\title{
Morfoanatomia comparada dos frutos em desenvolvimento de Vernonia brevifolia Less. e V. herbacea (Vell.) Rusby (Asteraceae) ${ }^{1}$
}

\author{
MARCO ANTONIO GARCIA MARTINS² e DENISE MARIA TROMBERT OLIVEIRA²,3,4
}

(recebido: 23 de fevereiro de 2006; aceito: 27 de dezembro de 2006)

\begin{abstract}
Comparative developmental morphology and anatomy of fruits of Vernonia brevifolia Less. and V. herbacea (Vell.) Rusby (Asteraceae)). In this work, the morphology, anatomy and ontogeny of the pericarp and pappus of Vernonia herbacea and V. brevifolia were described. Both species are very similar, possessing inferior, bicarpellate, syncarpous and unilocular ovary. In the pericarp formation, none region is multiplicative. The exocarp is uniseriate and recovered by thin cuticle. Long, multicellular and bisseriate non-glandular trichomes were observed, which persisted until maturity; capitate glandular trichomes are caducous. The outer mesocarp is composed of two or three fiber layers in V. herbacea, and only one in V. brevifolia, in both it accumulates prismatic crystals. In both species, the inner mesocarp is parenchymatous. Collateral vascular bundles occur immersed between outer and inner mesocarp. The endocarp is uniseriate, presenting two or three layers in the carpel fusing regions only. In the pericarp apical portion, there is a protuberance at the double pappus insertion, composed by lignified cells, some of them projected peripherally. At the fruit base, there is a carpopodium; in V. herbacea it is bigger and has druses and styloids; in V. brevifolia it is reduced and there is no crystals. At maturity, the pericarp of both species is dehydrated in such way that the cell layers are collapsed, and it is possible to distinguish only some exocarp cells and non-glandular trichomes, the outer mesocarpic fibers and crystals, and the xylem of vascular bundles.
\end{abstract}

Key words - anatomy, ontogeny, pappus, pericarp

RESUMO - (Morfoanatomia comparada dos frutos em desenvolvimento de Vernonia brevifolia Less. e V. herbacea (Vell.) Rusby (Asteraceae)). Neste trabalho, o pericarpo e pápus de Vernonia brevifolia e V. herbacea são descritos morfoanatômica e ontogeneticamente. As espécies são muito similares entre si, possuindo ovário ínfero, bicarpelar, sincárpico e unilocular. Na formação do pericarpo, nenhuma das regiões é multiplicativa. O exocarpo é unisseriado e recoberto por fina cutícula. Observamse tricomas tectores longos, multicelulares e bisseriados, que persistem até a maturidade; os tricomas glandulares capitados não se mantêm na maturidade. $\mathrm{O}$ mesocarpo externo é composto por duas ou três camadas de fibras em $V$. herbacea e apenas uma em V. brevifolia, acumulando cristais prismáticos. O mesocarpo interno é similar nas espécies, de natureza parenquimática. Feixes vasculares colaterais ocorrem imersos entre o mesocarpo externo e o interno. O endocarpo é unisseriado, havendo duas a três camadas apenas nas regiões de fusão dos carpelos. Na porção apical do pericarpo, observa-se uma protuberância onde se insere o pápus duplo, composto por células lignificadas, algumas projetadas perifericamente. Na base do fruto, ocorre o carpopódio que, em $V$. herbacea, é mais amplo e abriga drusas e estilóides; em V. brevifolia, o carpopódio é reduzido e não ocorrem cristais. Na maturidade, o pericarpo de ambas as espécies é desidratado, de modo que a maioria das camadas fica colapsada, distinguindo-se apenas algumas células do exocarpo e tricomas tectores, as fibras e cristais mesocárpicos externos e o xilema dos feixes vasculares.

Palavras-chave - anatomia, ontogênese, pápus, pericarpo

\section{Introdução}

O cerrado é um tipo de vegetação que se restringe ao Brasil, tendo pequenas áreas na Bolívia e no Paraguai

1. Parte da dissertação de mestrado do primeiro autor, Programa de Pós-graduação em Ciências Biológicas (Botânica), Universidade Estadual Paulista, Botucatu, SP, Brasil.

2. UNESP - Universidade Estadual Paulista, Instituto de Biociências, Departamento de Botânica, Caixa Postal 510, 18618-000 Botucatu, SP, Brasil.

3. Endereço atual: Universidade Federal de Minas Gerais, Instituto de Ciências Biológicas, Departamento de Botânica, Av. Antônio Carlos, 6627, Pampulha, Caixa Postal 486, 31270-901 Belo Horizonte, MG, Brasil.

4. Autor para correspondência: dmtoliveira@icb.ufmg.br
(Ratter 2004), ocorrendo em altitudes que variam de 300 a 1.600 m (Sano \& Almeida 1998). As campanhas conservacionistas têm sido eficazes em motivar as pessoas a protegerem as florestas e as árvores, mas plantas de pequeno porte e outros tipos de vegetação que não sejam florestas ainda são vistos como coisas sem importância, que podem ser eliminadas sem maiores conseqüências (Durigan et al. 2004). Estudos mostram que a taxa anual de desmatamento é alarmante no bioma, chegando a três milhões de hectares por ano (Machado et al. 2004). No Estado de São Paulo, apenas $1 \%$ da área original de cerrado ainda está coberta por vegetação nativa, sendo a conversão para agricultura a principal causa da devastação (Durigan et al. 2004). 
Ao contrário do que se supunha, a flora do cerrado é muito rica; foram contabilizadas no bioma 6.429 espécies de plantas vasculares, das quais 6.060 são angiospermas (Mendonça et al. 1998). Estimativas recentes indicam que o cerrado tem cerca de $10 \mathrm{mil}$ espécies de plantas superiores, estimando-se que $50 \%$ sejam espécies endêmicas (Ratter 2004). A família Asteraceae é a segunda mais bem representada no bioma (Almeida et al. 2005), com 106 gêneros e 557 espécies referidas por Mendonça et al. (1998). Muitas das espécies da família apresentam características de importância econômica, como o uso na medicina, na alimentação humana e animal, na ornamentação de ambientes e como invasoras de pastagens e culturas comerciais (Jones 1977).

Vernonia Schreb. (Cichorioideae) é o mais representativo entre os gêneros da tribo Vernonieae, abrangendo aproximadamente 1.000 espécies (Jones 1977, Bremer 1994); porém, a diferença na produção de certos compostos químicos (terpenos e flavonóides) entre espécies encontradas no velho e no novo mundo, justificaria a divisão deste gênero em outros menores, mantendo aproximadamente 500 espécies em Vernonia (Bremer 1994, Ortiz 1999), distribuídas pelo Sudeste da Ásia, África, especialmente em Madagascar, na América do Sul, América Central, México, Oeste da Índia e extremo Leste dos Estados Unidos (Jones 1977). Segundo o levantamento realizado por Mendonça et al. (1998), 92 espécies de Vernonia são encontradas no cerrado. $\mathrm{O}$ gênero tem importância medicinal e mais de 20 espécies já estão documentadas como curativas no sistema etno-medicinal (Johri \& Singh 1997).

Apesar da dimensão do gênero e de sua importância, poucos estudos estruturais com frutos foram realizados; Misra (1972) estudou V. anthelmintica (Linn.) Willd., Basak \& Mukherjee (2003) estudaram V. blanda D.C., $V$. galamensis Less., V. hymenolepis A. Rich., V. pyramidale (D.Don) S.N. Mitra, V. saligna D.C., $V$. stenolepis Oliver, V. teres Wall. e V. volkameriifolia H. Koyama e Pandey \& Singh (1980) estudaram $V$. altissima Nutt., $V$. anthelmintica, $V$. cinerea Less., $V$. fasciculata Michx. e V. missurica Raf.

Os frutos das Vernonia, assim como das demais espécies de Asteraceae, é enquadrado como aquênio ou cipsela, dependendo do autor consultado. Segundo Roth (1977), aquênio é um tipo especial de fruto seco, indeiscente, característico de Asteraceae, no qual o tegumento da semente e a parede do fruto são justapostos, porém independentes. Quando a dispersão é feita pelo vento, o fruto pode apresentar pápus, pêlos ou asas. A autora acrescenta que, além das características morfológicas, muitas características anatômicas podem ser utilizadas taxonomicamente, como o posicionamento de fibras e de esclereídes.

Bremer (1994) utiliza o termo cipsela, considerando os mesmos aspectos observados por Roth (1977) e acrescendo a origem em ovário ínfero; para o autor, assim como para Spjut (1994), aquênios são provenientes de ovários súperos. Em Vernonia, a cipsela apresenta pápus quase sempre duplo, raramente ausente, com cerdas pequenas ou escamas na camada externa e sendo coberto por pêlos persistentes ou não na camada interna (Cabrera 1944).

Pela grande freqüência na região de Botucatu e carência de estudos dos órgãos reprodutivos, foram escolhidas V. brevifolia Less. e V. herbacea (Vell.) Rusby para este estudo. Vernonia brevifolia é uma planta típica do Brasil e pode ser encontrada na região Sudoeste, desde Minas Gerais até o Rio Grande do Sul, Paraguai, Uruguai e Nordeste da Argentina até Entre Rios. É caracterizada como erva perene de base lenhosa e pouco espessada, com ramos eretos simples ou divididos no ápice, formando de duas a seis unidades. Seus espécimes podem alcançar de 20 a $40 \mathrm{~cm}$ de altura (Cabrera 1944).

Vernonia herbacea é uma planta medicinal que possui o sistema subterrâneo rico em frutanos do tipo inulina que, por hidrólise enzimática, podem constituir alternativa para a produção comercial de frutose (Pessoni et al. 2004).

Assim, o presente trabalho tem o objetivo de descrever a morfoanatomia e o desenvolvimento do fruto de $V$. brevifolia e $V$. herbacea, comparando-os entre si e com a literatura pertinente, buscando reconhecer padrões estruturais comuns entre as espécies, com o intuito de ampliar o conhecimento sobre aspectos estruturais de plantas típicas do bioma cerrado e fornecer subsídios para futuros trabalhos taxonômicos e filogenéticos envolvendo o grupo.

\section{Material e métodos}

O material botânico utilizado no trabalho constou de ovários retirados das inflorescências em várias fases do desenvolvimento, frutos jovens e maduros, coletados em áreas residuais de cerrado da região de Botucatu, SP, incluindo terrenos baldios e margem de ferrovia. Espécimes de Vernonia brevifolia (sinonímia: Cacalia brevifolia (Less.) Kuntze. e Lessingianthus breviflorus Less.; coordenadas:

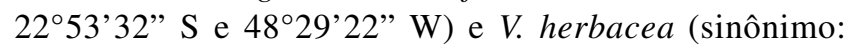
Chrysocona herbacea Vell.; coordenadas: $22^{\circ} 53^{\prime} 36^{\prime \prime} \mathrm{S}$ e $48^{\circ} 29^{\prime} 51^{\prime \prime}$ W) foram herborizados e depositados no Herbário 
"Irina D. Gemtchujnicov" (BOTU) do Departamento de Botânica, UNESP, Câmpus de Botucatu, respectivamente sob os números 24.456 e 24.407.

Os estudos morfoanatômicos foram realizados em material fresco ou fixado em FAA, preparado com etanol $50 \%$ (Johansen 1940), e conservado em álcool etílico a 70\% (Jensen 1962).

Para elaboração de laminário permanente, após desidratação em série etílica e inclusão em metacrilato (Leica®), o material foi seccionado em micrótomo rotatório com cerca de $8 \mu \mathrm{m}$ de espessura, obtendo-se séries transversais e longitudinais. As secções obtidas foram coradas com azul de toluidina a $0,05 \%$ em tampão acetato $\mathrm{pH}$ 4,7 (O’Brien et al. 1964) e montadas em Entellan®.

Alguns cortes de material fixado foram preparados para a realização de testes histoquímicos, sendo utilizados os seguintes corantes e reagentes: vermelho de rutênio, para identificar polissacarídeos diversos e pectinas (Jensen 1962); floroglucinol em meio ácido, para evidenciar paredes lignificadas (Sass 1951); Sudan IV, para localização de substâncias lipídicas; lugol, para localização de amido; cloreto férrico, para verificar a ocorrência de compostos fenólicos; ácido acético concentrado e ácido sulfúrico a 10\%, para verificar a composição química dos cristais (Johansen 1940).

Para a análise do pápus, foram também confeccionadas lâminas semipermanentes, a partir da separação de suas unidades, as quais foram coradas com safranina aquosa a $1 \%$ e montadas em glicerina a $50 \%$, sendo lutadas com esmalte.

A terminologia adotada foi de Roth (1977). Para a caracterização do pericarpo, considerou-se a parede ovariana como um todo, sem destacar a extensão dos tecidos receptaculares, visto que os dois não são claramente distintos; deste modo, considerou-se que a epiderme externa do ovário ínfero produziu o exocarpo, a região fundamental e vascular constituiu o mesocarpo e a epiderme interna formou o endocarpo.

Os resultados foram ilustrados por meio de fotomicrografias obtidas em fotomicroscópio Zeiss, acrescentando-se escalas nas condições ópticas adequadas.

\section{Resultados}

Ovário (figuras 1-3) - A fase inicial do desenvolvimento do fruto de $V$. brevifolia e $V$. herbacea é compreendida pelo ovário de botões florais e flores em antese.

O ovário das duas espécies é ínfero (figuras 1-2), bicarpelar, sincárpico e unilocular (figura 3). A epiderme externa é unisseriada, composta por células cubóides justapostas e de paredes delgadas, citoplasma denso, núcleos evidentes (figura 3) e recobertas por cutícula muito delgada. Numerosos tricomas tectores e glandulares encontram-se em início de diferenciação (figuras 1-3).
O mesofilo exibe duas regiões distintas (figura 3). A mais externa, aqui referida como mesofilo externo, apresenta de uma a três camadas de células em $V$. herbacea e apenas uma camada em V. brevifolia. Em ambas espécies, as células do mesofilo externo apresentam formato ligeiramente alongado radialmente em corte transversal (figura 3) e intenso alongamento longitudinal (figuras 1-2), com paredes delgadas e núcleos também alongados e evidentes (figuras 2-3). O mesofilo interno, mostra de seis a nove camadas de células com formatos variáveis (figuras 1-3), mais longas e largas que as periféricas, de paredes finas, citoplasma pouco denso e núcleos evidentes. Imersos no mesofilo, observam-se cordões procambiais (figura 3 ) iniciando a diferenciação de elementos traqueais, dispostos entre o mesofilo externo e interno.

A epiderme interna é composta por uma única camada de células de contorno retangular em corte transversal, com paredes delgadas, citoplasma denso e núcleo evidente (figura 3). Ainda na epiderme interna, destacam-se as duas regiões da fusão marginal dos dois carpelos (figura 3), onde a epiderme é multisseriada e as células são pequenas, mais densas, com núcleos grandes e bem evidentes.

$\mathrm{Na}$ região basal do ovário, observa-se a formação de uma protuberância preenchida por células parenquimáticas de formato irregular e paredes delgadas (figuras 1-2), o carpopódio. Em V. herbacea, essa protuberância é mais ampla (figura 2) e suas células apresentam início da formação de cristais (figura 4), havendo drusas em formação e estilóides. Em V. brevifolia, o número de células que compõem o carpopódio é menor (figura 1) e não se verificou a formação de cristais.

Fruto jovem (figuras 5-26) - Nesta fase, verifica-se que nenhuma região do pericarpo é multiplicativa, não se reconhecendo atividade meristemática no fruto (comparar as figuras 1 e 5, referentes a V. brevifolia, e as figuras 2-3 com 10 e 12, $V$. herbacea). O exocarpo é, portanto, formado por epiderme unisseriada com células de formatos e tamanhos variáveis, paredes finas e recobertas por cutícula muito delgada, como o observado no ovário; os núcleos são evidentes e as células mostram-se mais volumosas e vacuolizadas (figuras 6-8, 11-12, 14-19). Os tricomas já se mostram mais diferenciados, observando-se que os tectores (figuras 6, 11) são longos, multicelulares e bisseriados; suas duas células apicais são alongadas e de paredes espessadas (figura 9) e lignificadas, apresentando pontoações; as células basais são maiores do que as demais células da epiderme e podem apresentar 

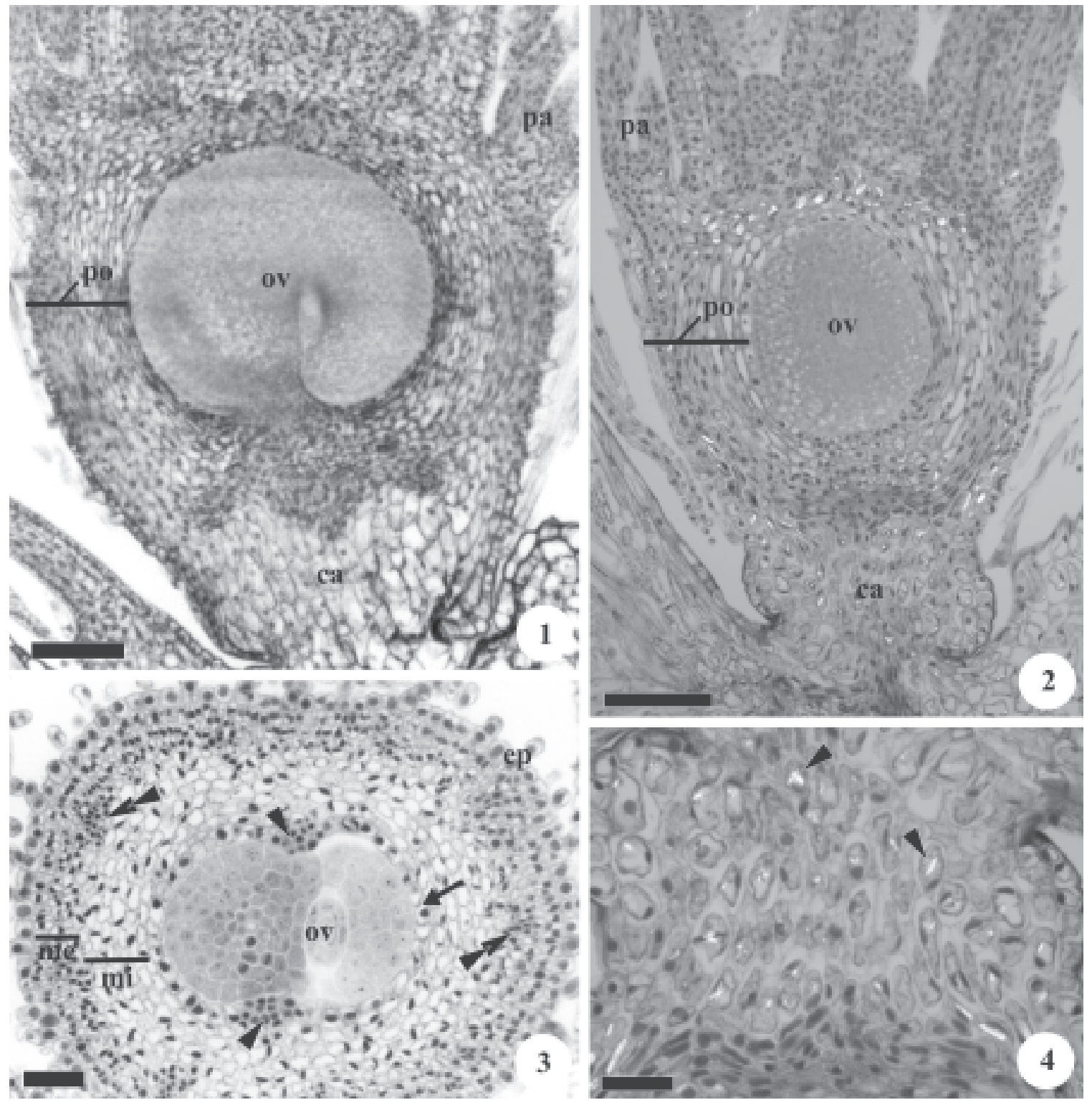

Figuras 1-4. Ovário de botão floral e flor em antese. Secções longitudinais (1-2,4). Secção transversal (3). 1. Vernonia brevifolia. 2-4. V. herbacea. 2. Aspecto geral sob luz polarizada. 3. Aspecto geral, mostrando tricomas na epiderme externa, mesofilo externo mais denso e interno mais vacuolado, e a epiderme interna (seta); notar também as células das regiões de fusão carpelar (pontas de seta) e cordões procambiais com pequena diferenciação (dupla ponta de seta). 4. Detalhe do carpopódio sob luz polarizada; notar cristais em diferenciação (ponta de seta). ( $c a=$ capopódio; ep = epiderme; me = região externa do mesofilo; $\mathrm{mi}=$ região interna do mesofilo; ov = óvulo; pa = pápus; po = parede ovariana). Barras = $150 \mu \mathrm{m}(2), 100 \mu \mathrm{m}(1), 50 \mu \mathrm{m}(3-4)$.

Figures 1-4. Ovary of floral bud and flower at anthesis. Longitudinal sections (1-2). Transverse section (3). 1. Vernonia brevifolia. 2-3. V. herbacea. 2. General view under polarized light. 3. General view, showing trichomes in outer epidermis, outer and inner mesophyll more vacuolated, and the inner epidermis (arrow); notice the cells of the carpel fusing regions (arrowheads) and poor differentiated procambial strands (double arrowhead). 4. Detail of the carpopodium under polarized light; note cystals in differentiation (arrowhead). $(\mathrm{ca}=$ carpopodium; $\mathrm{ep}=$ epidermis; $\mathrm{me}=$ outer region of mesophyll; $\mathrm{mi}=$ inner region of mesophyll; $\mathrm{ov}=$ ovule; $\mathrm{pa}=$ pappus; $\mathrm{po}=$ ovarian wall). Bars $=150 \mu \mathrm{m}(2), 100 \mu \mathrm{m}(1), 50 \mu \mathrm{m}(3-4)$. 


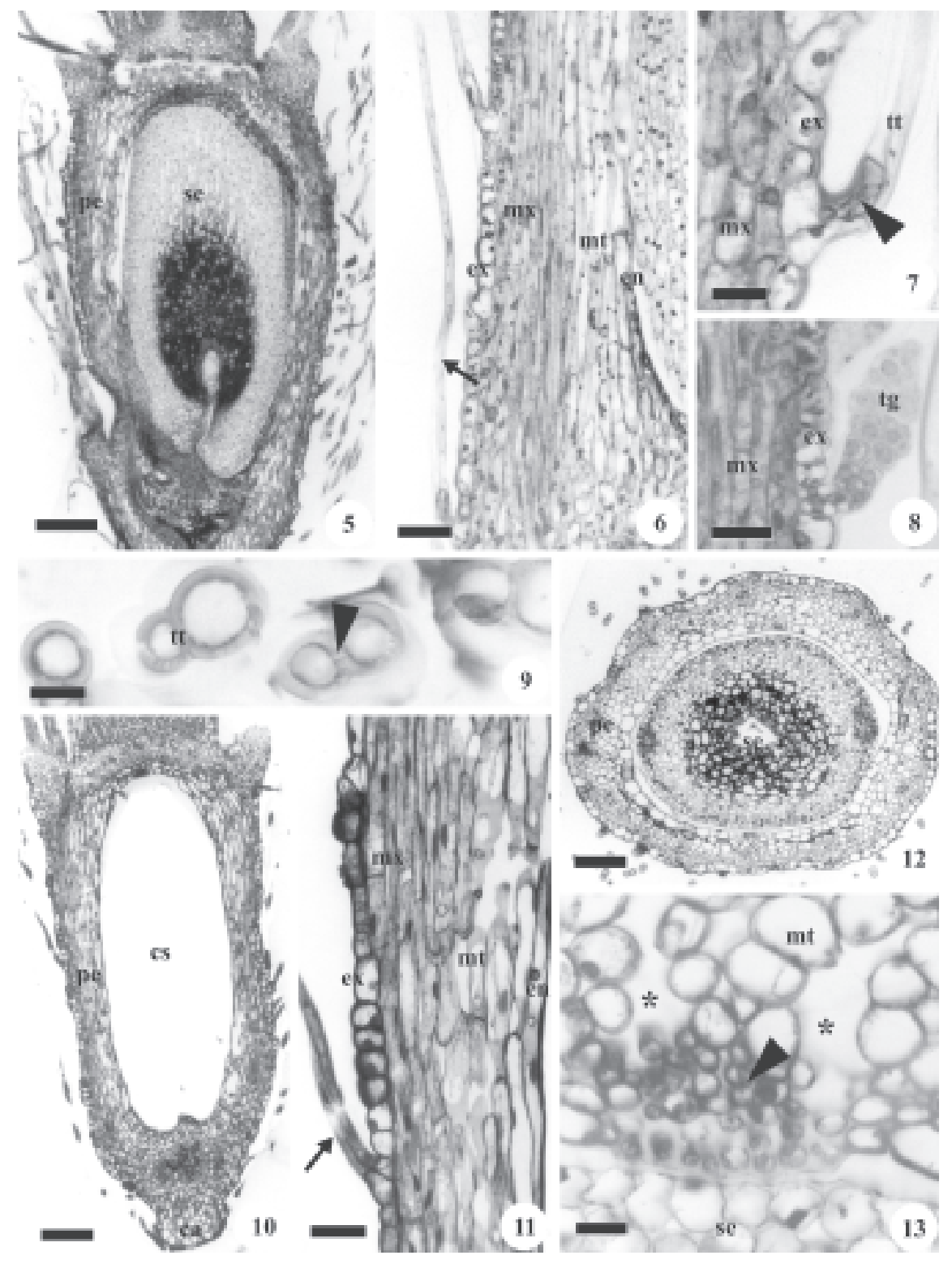

Figuras 5-13. Pericarpo jovem. Secções longitudinais (5-8, 10-11). Secções transversais (9, 12-13). 5-9. Vernonia brevifolia. 5. Aspecto geral do fruto com semente. 6. Detalhe do pericarpo, destacando o exocarpo com tricomas tectores (seta). 7. Detalhe da base do tricoma tector, mostrando sua inserção bisseriada no exocarpo (ponta de seta = compostos fenólicos). 8. Detalhe de tricoma glandular também com base bisseriada. 9. Detalhe do tricoma tector bisseriado, mostrando paredes espessadas com pontoação (ponta de seta). 10-13. V. herbacea. 10. Aspecto geral do fruto sem semente. 11. Detalhe do pericarpo, mostrando exocarpo com tricoma tector (seta). 12. Vista geral do fruto com semente. 13. Detalhe do mesocarpo interno laxo (asterisco = espaço intercelular) e endocarpo na região de fusão carpelar (ponta de seta). (ca = carpopódio; cs = cavidade seminal; en = endocarpo $; \mathrm{ex}=$ exocarpo $; \mathrm{mx}=$ mesocarpo externo; $\mathrm{mt}=$ mesocarpo interno; $\mathrm{pe}=$ pericarpo $; \mathrm{se}=$ semente $; \mathrm{tg}=$ tricoma glandular; $\mathrm{tt}=$ tricoma tector $)$. Barras $=200 \mu \mathrm{m}(5,10), 100 \mu \mathrm{m}(12), 50 \mu \mathrm{m}(6,11), 25 \mu \mathrm{m}(7-8), 10 \mu \mathrm{m}(9,13)$.

Figures 5-13. Young pericarp. Longitudinal sections (5-8, 10-11). Transverse sections (9, 12-13). 5-9. Vernonia brevifolia. 5. General aspect of the fruit with seed. 6. Detail of pericarp; note exocarp with non-glandular trichomes (arrow). 7. Detail of the non-glandular trichome base, showing its bisseriate insertion in exocarp (arrowhead = phenolic compounds). 8. Detail of the glandular trichome with bisseriate base. 9. Detail of the bisseriate non-glandular trichome, showing thick walls with pit (arrowhead). 10-13. V. herbacea. 10. General aspect of the fruit without seed. 11. Detail of the pericarp, showing exocarp with non-glandular trichome (arrow). 12. General view of the fruit with seed. 13. Detail of the loose inner mesocarp (asterisk = intercellular space) and of the endocarp in the carpel fusing region (arrowhead). (ca = carpopodium; cs = seminal cavity; en = endocarp; ex = exocarp; $\mathrm{mx}=$ outer mesocarp; $\mathrm{mt}=$ inner mesocarp; $\mathrm{pe}=$ pericarp; $\mathrm{se}=\mathrm{seed}$; $\mathrm{tg}=$ glandular trichome; $\mathrm{tt}=$ nonglandular trichome). Bars $=200 \mu \mathrm{m}(5,10), 100 \mu \mathrm{m}(12), 50 \mu \mathrm{m}(6,11), 25 \mu \mathrm{m}(7-8), 10 \mu \mathrm{m}(9,13)$. 


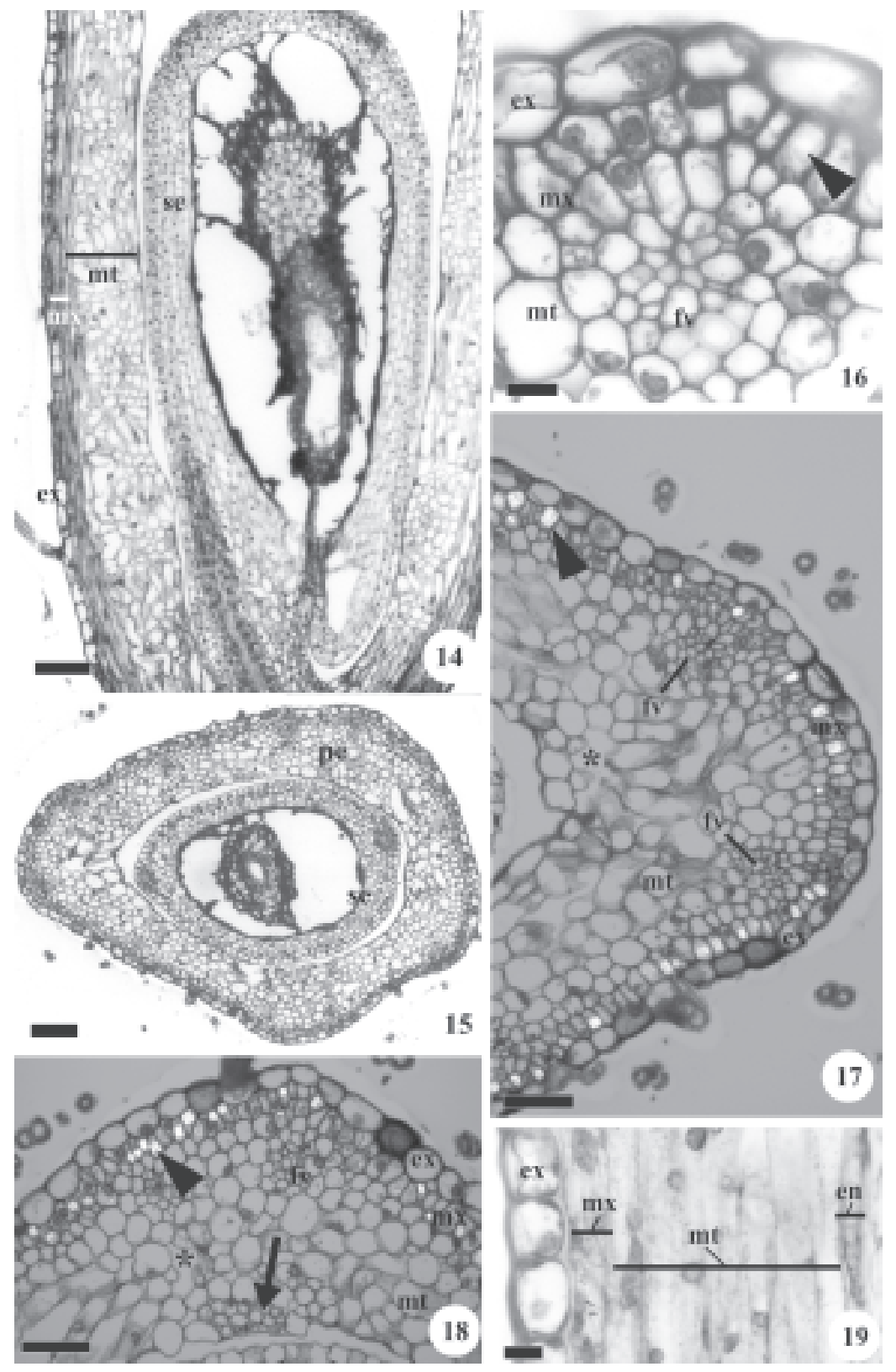

Figuras 14-19. Pericarpo de Vernonia brevifolia em desenvolvimento. Secções longitudinais $(14,19)$. Secções transversais (15-18). 14-15. Aspecto geral, destacando as células mesocárpicas internas com formatos variáveis e meatos. 16. Detalhe do exocarpo e mesocarpo, mostrando um feixe vascular colateral (ponta de seta $=$ cristal). 17. Detalhe do pericarpo com feixes vasculares, vistos sob luz polarizada; notar o mesocarpo externo coeso (ponta de seta $=$ cristal) e o interno de aspecto laxo (asterisco = espaço intercelular). 18. Detalhe do pericarpo na região de fusão carpelar, sob luz polarizada (asterisco = espaço intercelular; ponta de seta $=$ cristal; seta $=$ células endocárpicas de tamanho pequeno). 19 . Detalhe do pericarpo, destacando $\mathrm{o}$ alongamento longitudinal das células mesocárpicas. $(\mathrm{en}=$ endocarpo; $\mathrm{ex}=$ exocarpo; $\mathrm{fv}=$ feixe vascular; $\mathrm{mt}=$ mesocarpo interno; $\mathrm{mx}=$ mesocarpo externo; $\mathrm{pe}=$ pericarpo; se = semente). Barras $=100 \mu \mathrm{m}(14-15), 50 \mu \mathrm{m}(17-18), 10 \mu \mathrm{m}(16,19)$.

Figures 14-19. Pericarp of Vernonia brevifolia during development. Longitudinal sections (14, 19). Transverse sections (15-18). 14-15. General aspect; note the inner mesocarpic cells with variable forms and spaces. 16. Detail of exocarp and mesocarp, showing a collateral vascular bundle (arrowhead $=$ crystal). 17. Detail of pericarp with vascular bundles, observed under polarized light; note outer mesocarp without spaces (arrowhead $=$ crystal) and the inner one loose (asterisk $=$ intercellular space). 18. Detail of pericarp in the carpel fusing region, observed under polarized light (asterisk = intercellular space; arrowhead $=$ crystal arrow $=$ small endocarpic cells). 19 . Detail of pericarp; note the longitudinal elongation of the mesocarpic cells. $(\mathrm{en}=$ endocarp; $\mathrm{ex}=$ exocarp; $\mathrm{fv}=$ vascular bundle; $\mathrm{mt}=$ inner mesocarp; $\mathrm{mx}=$ outer mesocarp; $\mathrm{pe}=$ pericarp; $\mathrm{se}=$ seed $)$. Bars $=100 \mu \mathrm{m}(14-15), 50 \mu \mathrm{m}(17-18), 10 \mu \mathrm{m}(16,19)$. 
conteúdo fenólico (figura 7). Os tricomas glandulares (figura 8) também mostram base composta por duas células de conteúdo pouco denso, paredes delgadas e núcleo evidente; a porção secretora apical é multicelular, formada por células de paredes delgadas, com citoplasma denso e núcleos bem evidenciados; os testes realizados indicam secreção de natureza péctica.

No mesocarpo, a diferenciação em duas regiões é mantida (figuras 11-12, 14-15, 22). O mesocarpo externo é composto por uma a três camadas de células justapostas e alongadas longitudinalmente em $V$. herbacea (figuras 22, 26) e apenas uma camada em $V$. brevifolia (figuras 16, 19); em ambas as espécies, estas células apresentam início de espessamento das paredes celulares e formação de cristais prismáticos (figuras 16-18, 23, 25-26). O mesocarpo interno não mostra diferenças entre as espécies, sendo composto por aproximadamente seis a nove camadas de células parenquimáticas (figuras 14, 22), com contornos e tamanhos irregulares no plano transversal (figuras 17-18, 23), muito alongadas e sinuosas longitudinalmente (figuras 14, 22); suas paredes celulares são delgadas e o citoplasma é pouco denso. Observam-se evidentes espaços intercelulares dispersos por todo o mesocarpo interno (figuras 13, 17-18, 23), que são comprimidos durante o desenvolvimento (figura 25). Imersos entre o mesocarpo externo e o interno, verificam-se feixes vasculares colaterais (figuras 16-17, 23).

O endocarpo é composto por uma única camada de células que variam de aproximadamente isodiamétricas a ligeiramente alongadas tangencialmente no plano transversal, de paredes delgadas e citoplasma pouco denso (figuras 18, 23); no plano longitudinal, células endocárpicas são bastante alongadas (figura 19). Nas regiões de fusão dos carpelos, o endocarpo mantémse multisseriado e suas células apresentam-se bem menores que as demais, com citoplasma mais denso e núcleo bem evidente (figuras 18, 23).

$\mathrm{Na}$ porção apical do pericarpo, observa-se a formação de uma protuberância preenchida por células de formatos irregulares e paredes delgadas, recobertas por epiderme unisseriada, sobre as quais se insere o pápus (figuras 20-21). Internamente, nota-se a formação de um disco de fibras com paredes espessadas e lignificadas, dispostas obliquamente, apresentando cristais prismáticos de oxalato de cálcio e conteúdo fenólico, sobre as quais se inserem a corola e o androceu (figuras 20-21).

O carpopódio não mostra mudanças anatômicas nesta fase, só sendo observados drusas e estilóides em
V. herbacea (figura 24) e a ausência de cristais em V. brevifolia.

O pápus é duplo (figura 21) e composto por um conjunto multisseriado de células de contorno arredondado transversalmente e alongadas longitudinalmente, cujas extremidades apicais externas projetam-se para o exterior.

Fruto maduro (figuras 27-34) - Corresponde à estrutura do fruto próximo à dispersão. Nesta fase, o pericarpo apresenta intensa desidratação, de modo que a maioria das camadas fica colapsada (figuras 27, 29). Distinguem-se, apenas, algumas células exocárpicas e tricomas tectores, as fibras e cristais mesocárpicos externos e os feixes vasculares (figuras 28,30 ). As demais regiões apresentam somente as paredes celulares sobrepostas, que permanecem adjacentes ao tegumento seminal. Assim, na maturidade, o pericarpo de $V$. herbacea mostra maior espessura (figuras 29-30) que o de V. brevifolia (figuras 27-28), visto que aquele apresenta maior número de camadas de fibras mesocárpicas.

No pápus (figuras 31-34), as paredes celulares apresentam-se completamente lignificadas e mostram pontoações (figuras 31,33). Observa-se a freqüente presença de fungos, com micélios septados de coloração marrom, apoiados principalmente nas projeções formadas pelas células superficiais das cerdas do pápus (figuras 32, 34).

\section{Discussão}

As características gerais do ovário de Vernonia brevifolia e $V$. herbacea, referentes à posição, número e fusão de carpelos, concordam com a literatura disponível para as Asteraceae (Roth 1977, Pandey \& Singh 1980, Bremer 1994, Barroso et al. 1999).

O desenvolvimento da parede ovariana, nas duas espécies aqui estudadas, assemelha-se à descrições feitas por Misra (1972) para $V$. anthelmintica e Pandey \& Singh (1980) para $V$. anthelmintica, V. altissima, $V$. cinerea, $V$. fasciculata e $V$. missurica, com a parede ovariana dividida em quatro regiões: a epiderme externa, o mesofilo externo e interno e a epiderme interna.

Um fato que chama a atenção no ovário das espécies de Vernonia em estudo é o aumento da espessura da epiderme interna restrito às regiões de fusão carpelar. Misra (1972) e Pandey \& Singh (1980) chamam esta região de tecido de transmissão, o que sugere que tais células possam ser relacionadas ao encaminhamento dos tubos polínicos até a base do ovário, onde se encontra inserido o único óvulo. 


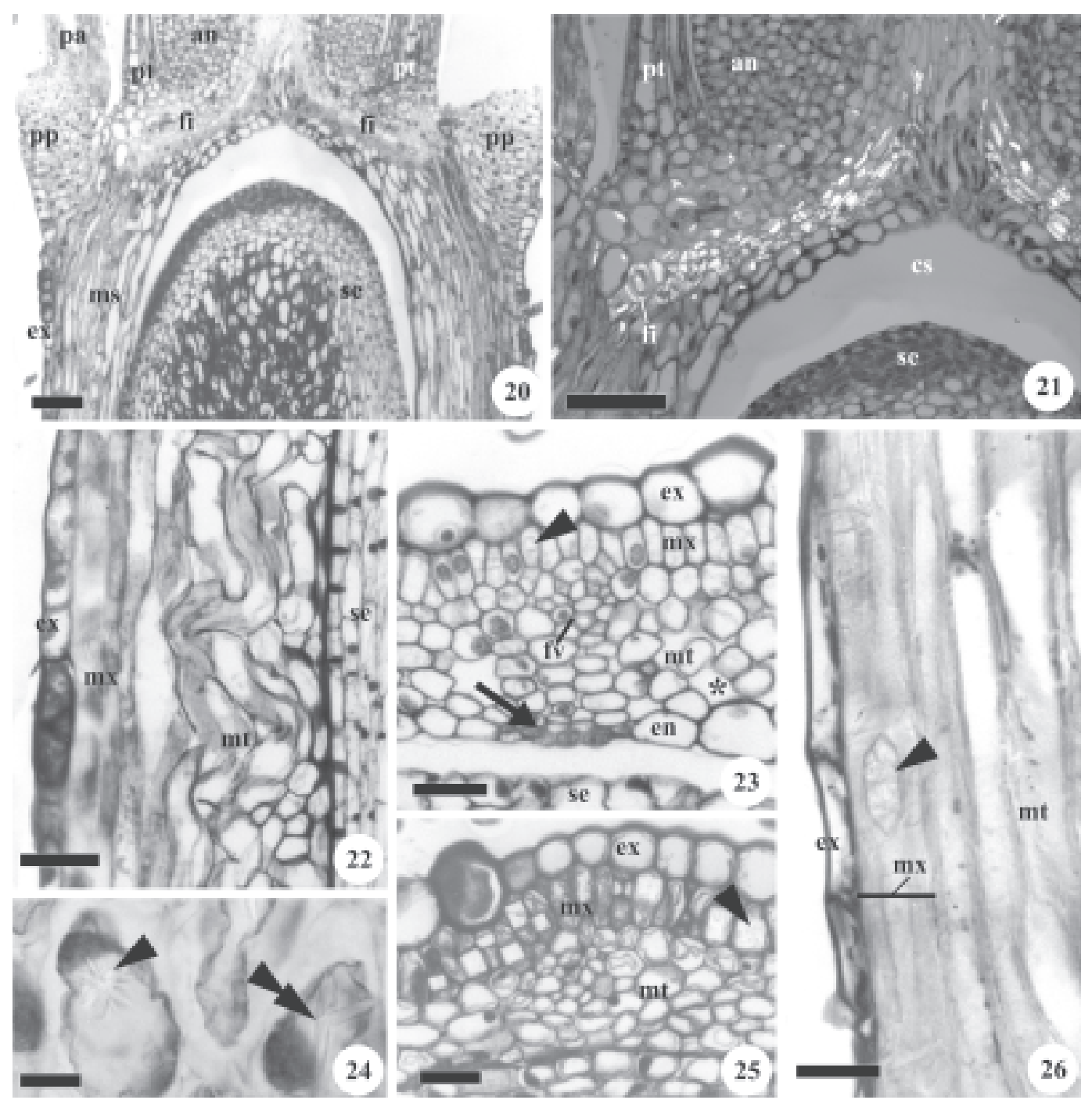

Figuras 20-26. Pericarpo de Vernonia herbacea em desenvolvimento. Secções longitudinais (20-22, 24, 26). Secções transversais $(23,25)$. 20. Região apical mostrando o disco de fibras. 21. Detalhe da inserção do pápus sobre a protuberância de células parenquimáticas de paredes delgadas. 22-23. Aspecto geral do pericarpo; notar o formato e arranjo das células do mesocarpo externo (ponta de seta $=$ cristal) e interno (asterisco = espaço intercelular), bem como as células endocárpicas diferenciadas na região de fusão carpelar (seta). 24. Detalhe da região basal, com destaque para os cristais do tipo drusa (ponta de seta) e estilóides (dupla ponta de seta). 25. Aspecto de pericarpo próximo à maturação, destacando o espessamento das paredes celulares no mesocarpo externo e a redução dos meatos no mesocarpo interno (ponta de seta=cristais). 26. Detalhe do mesocarpo, mostrando cristal prismático (ponta de seta) no mesocarpo externo. $($ an $=$ androceu; $\mathrm{cs}=$ cavidade seminal; en $=$ endocarpo; $\mathrm{ex}=$ exocarpo; $\mathrm{fi}=$ fibras; $\mathrm{fv}=$ feixe vascular; $\mathrm{ms}=$ mesocarpo $; \mathrm{mt}=$ mesocarpo interno $; \mathrm{mx}=$ mesocarpo externo; $\mathrm{pa}=$ pápus; $\mathrm{pp}=$ projeção onde se insere o pápus; $\mathrm{pt}=$ pétala; $\mathrm{se}=$ semente). Barras $=100 \mu \mathrm{m}(20-21), 50 \mu \mathrm{m}(22), 25 \mu \mathrm{m}$ $(23,25), 10 \mu \mathrm{m}(24,26)$.

Figures 20-26. Pericarp of Vernonia herbacea during development. Longitudinal sections (20-22, 24, 26). Transverse sections $(23,25)$. 20. Apical region showing the fiber disc. 21. Detail of the pappus insertion on the lump of thin walls parenchyma cells. 22-23. General aspect of pericarp; note the form and arrangement of the outer (arrowhead = crystal) and inner mesocarp cells (asterisk = intercellular space), and the endocarpic cells differentiated in the carpel fusing region (arrow). 24. Detail of the basal region, with druses (arrowhead) and styloids (double arrowhead). 25. Aspect of the pericarp near to maturation; note the thickening of the outer mesocarp cell walls and the reduction of spaces in inner mesocarp (arrowhead $=$ crystals). 26. Detail of the mesocarp, showing outer mesocarp prismatic crystal (arrowhead). $($ an $=$ androecium; $\mathrm{cs}=$ seed chamber; en $=$ endocarp; $\mathrm{ex}=$ exocarp; fi = fiber; $\mathrm{fv}=$ vascular bundle; $\mathrm{ms}=$ mesocarp; $\mathrm{mt}=$ inner mesocarp; $\mathrm{mx}=$ outer mesocarp; $\mathrm{pa}=$ pappus; $\mathrm{pp}=$ projection where the pappus is disposed; $\mathrm{pt}=$ petal; se = seed). Bars $=100 \mu \mathrm{m}(20-21), 50 \mu \mathrm{m}(22), 25 \mu \mathrm{m}(23,25), 10 \mu \mathrm{m}$ $(24,26)$. 

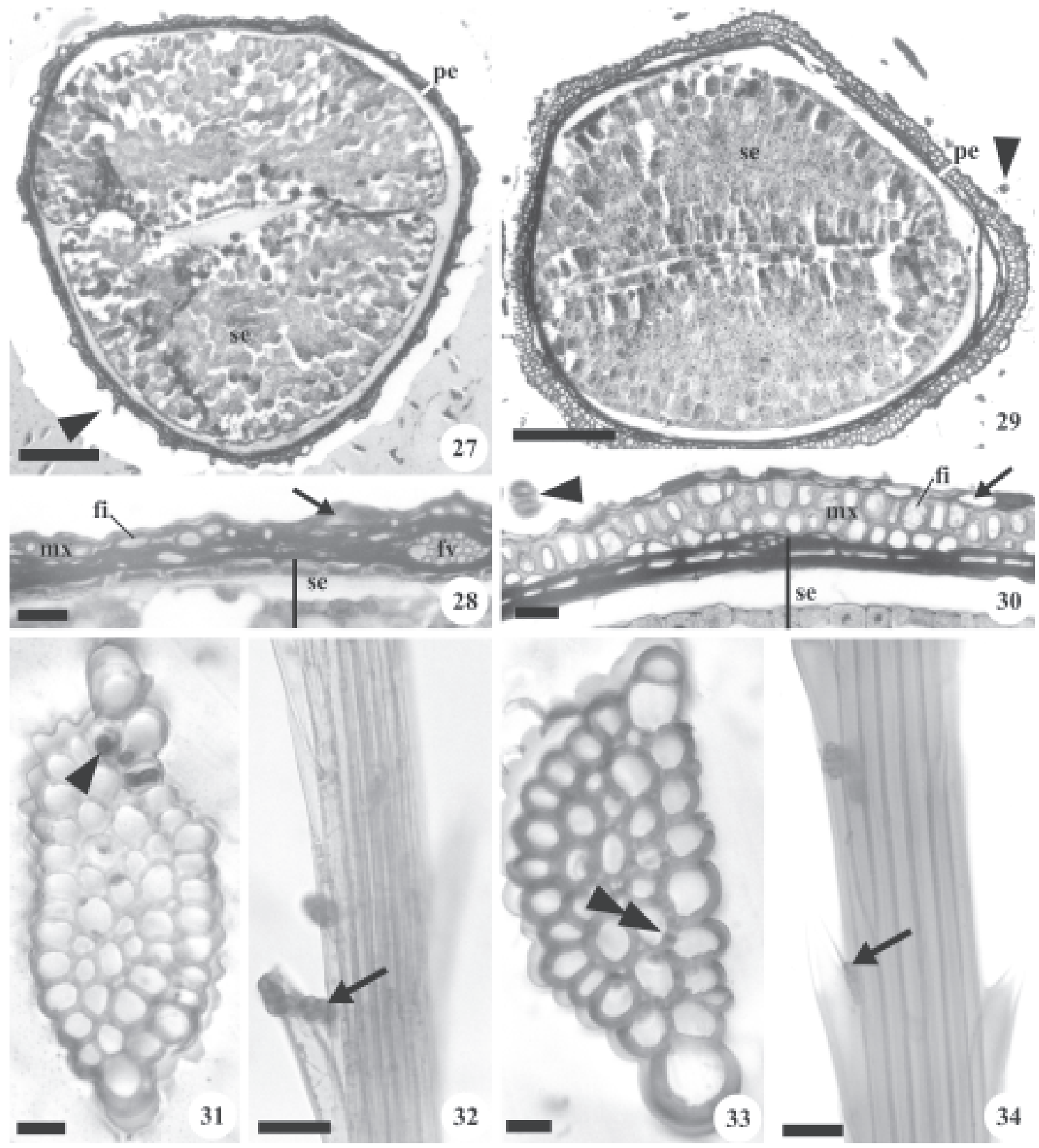

Figuras 27-34. Fruto maduro. Secções longitudinais (32, 34). Secções transversais (27-30, 31, 33). 27-28. Pericarpo de Vernonia brevifolia. 27. Aspecto geral da secção mediana (ponta de seta = tricoma tector). 28. Detalhe do pericarpo maduro desidratado, destacando um feixe vascular (seta = exocarpo). 29-30. Pericarpo de V. herbacea. 29. Aspecto geral da secção mediana (ponta de seta $=$ tricoma tector). 30 . Detalhe do pericarpo maduro desidratado (ponta de seta $=$ tricoma tector; seta $=$ exocarpo). 31-34. Pápus (ponta de seta = células com conteúdo fenólico; dupla ponta de seta = pontoação; seta = projeção de célula superficial com presença de fungos). 31-32. V. brevifolia. 33-34. V. herbacea.$(\mathrm{fi}=$ fibras; $\mathrm{fv}=$ feixe vascular; $\mathrm{mx}=\mathrm{mesocarpo}$ externo; pe $=$ pericarpo, $\mathrm{se}=$ semente $)$. Barras $=200 \mu \mathrm{m}(27,29), 25 \mu \mathrm{m}(28,30,32,34), 10 \mu \mathrm{m}(31,33)$.

Figures 27-34. Mature fruit. Longitudinal sections (32, 34). Transverse sections (27-30, 31, 33). 27-28. Vernonia brevifolia. pericarp. 27. General aspect of medium section ( arrowhead $=$ non-glandular trichome). 28. Detail of mature dehydrated pericarp; note a vascular bundle (arrow = exocarp). 29-30. V. herbacea pericarp. 29. General aspect of medium section $($ arrowhead = nonglandular trichome). 30. Detail of mature dehydrated pericarp (arrowhead $=$ non-glandular trichome; arrow $=$ exocarp). 31-34. Pappus (arrowhead $=$ cells with phenolic content; double arrowhead $=$ pit; arrow $=$ superficial cell projection with the presence of fungi). 31-32. V. brevifolia. 33-34. V. herbacea . $(\mathrm{fi}=$ fibers; $\mathrm{fv}=$ vascular bundle; $\mathrm{mx}=$ outer mesocarp; pe = pericarp, $\mathrm{se}=$ seed $)$. Bars $=200 \mu \mathrm{m}(27,29), 25 \mu \mathrm{m}(28,30,32,34), 10 \mu \mathrm{m}(31,33)$. 
Na porção central no ápice do ovário, Pandey \& Singh (1980) observaram, nas Vernonia por eles estudadas, um conjunto de células de paredes espessadas, com presença de cristais. Neste trabalho, verificou-se que tanto $V$. brevifolia quanto $V$. herbacea somente formam estas fibras em fase posterior, no início do desenvolvimento do fruto.

Com relação ao estudo do pericarpo, a definição de exo, meso e endocarpo varia de acordo com o ponto de vista de cada autor. A maioria dos autores prefere utilizar o conceito ontogenético, em que os termos exo e endocarpo incluem, além das epidermes externa e interna, respectivamente, também os tecidos subepidérmicos produzidos por divisões periclinais (Roth 1977). De acordo com Fahn (1990), a separação do pericarpo em três camadas distintas facilita a descrição anatômica, mas elas não necessariamente representam tecidos separados do ponto de vista de sua origem; o autor aplica, portanto, o conceito morfológico e não ontogenético. Neste trabalho, adotou-se o conceito ontogenético, sensu Roth (1977).

Também merece destaque o caráter não multiplicativo do pericarpo das espécies estudadas. A proliferação de camadas no início do desenvolvimento é freqüiente em vários tipos de fruto, embora seja mais ampla em pericarpos carnosos. Em frutos secos, a presença ou ausência de ampliação de camadas celulares no pericarpo está condicionada ao tipo de fruto e seu papel com relação à proteção e/ou dispersão da semente. Pericarpos protetores de frutos secos indeiscentes e pericarpos secos deiscentes tendem a ser multiplicativos, de modo que pode ocorrer a diferenciação de vários tecidos, em especial do esclerênquima, respectivamente realizando a proteção da semente ou atuando na deiscência. Em V. brevifolia e $V$. herbacea, a característica dispersão anemocórica é favorecida pela pequena dimensão do pericarpo, bem como pela compressão quase total das camadas de células de paredes delgadas, que conferem leveza ao diásporo, além do investimento na formação do pápus, estrutura especializada no transporte pelo vento (Pijl 1982).

Também com relação ao processo de desenvolvimento do pericarpo, nota-se grande constância entre espécies de Vernonia. Tanto em $V$. brevifolia e $V$. herbacea, quanto nas espécies estudadas por Misra (1972) e Pandey \& Singh (1980), nota-se o espessamento e lignificação das células do mesocarpo externo e a compressão do mesocarpo interno. Entre as espécies, verificou-se que varia, apenas, o número de camadas de cada região.
Nas espécies estudadas, observou-se intensa desidratação na maturidade pericárpica, distinguindo-se, apenas, algumas células exocárpicas e células de paredes espessas, como as fibras mesocárpicas externas e o xilema nos feixes. As demais regiões mostram-se colapsadas, diferente do relatado para V. fasciculata e V. missurica, que apresentam, segundo Pandey \& Singh (1980), o mesocarpo interno não colapsado, formado por células parenquimáticas de paredes delgadas. Outras espécies de Vernonia relatadas por Tiagi \& Taimni (1960) e por Misra (1972) também apresentam colapso das camadas internas; assim, o registrado para $V$. fasciculata e $V$. missurica caracteriza uma exceção.

Com relação à presença de tricomas, no exocarpo de $V$. brevifolia e $V$. herbacea ocorrem apenas os tectores, sendo os glandulares restritos às estruturas jovens. Cabrera (1944) relatou para Vernonia também tricomas glandulares unicelulares, não encontrados nas espécies em estudo. Em V. brevifolia e V. herbacea, o tricoma glandular observado tem base com duas células e corpo multicelular, mais parecido com um dos tricomas descritos para as folhas de espécies da subtribo Madinae (Heliantheae) por Carlquist (1958).

Em V. altissima, $V$. cinerea e $V$. anthelmintica, Tiagi \& Taimni (1960), Misra (1972) e Pandey \& Singh (1980) observaram, além dos tricomas tectores, a persistência de tricomas glandulares na maturidade, fato não corroborado pelo presente estudo.

O tipo de tricoma tector aqui descrito parece ser de ocorrência ampla nas Asteraceae, tendo sido registrado por Pandey et al. (1978) em Tragopogon L. (Cichorieae), por Davies \& Facher (2001) no gênero Chaetanthera Ruiz \& Pav. (Mutiseae) e por Cabrera (1944) em Vernonia Schreb.

Conforme registrada neste trabalho, a principal diferença entre os pericarpos de $V$. brevifolia e $V$. herbacea é o número de camadas do mesocarpo externo (respectivamente uma e de duas a três). Embora este caráter seja suficiente para distinguir estas espécies entre si, há relatos na literatura de variação do número de camadas (de uma a quatro) em diferentes regiões de um mesmo fruto, o que foi observado em $V$. cinerea (Tiagi \& Taimni 1960, Pandey \& Singh 1980), V. fasciculata, V. missurica (Pandey \& Singh 1980) e V. anthelmintica (Misra 1972, Pandey \& Singh 1980). Deste modo, o caráter não deve ser aplicado sem o devido cuidado.

O pápus encontrado nas cipselas é uma fonte clássica de informação taxonômica e dependendo do grau de especificidade das características, pode ser 
utilizado para identificação de gêneros e espécies (Mukherjee \& Sarkar 2001). Em V. brevifolia e $V$. herbacea, o pápus é duplo, com a fileira interna mais longa que a externa, típico de Vernonia e Piptocarpha R.Br. (Cabrera 1944), e as células superficiais apresentam projeções. Pandey \& Singh (1980) não detalharam o pápus das cipselas das espécies estudadas, apenas descreveram como curto em $V$. cinerea, longo em $V$. altissima e $V$. missurica, ou formado apenas por pequenos pêlos, em $V$. anthelmintica e V. fasciculata. Quanto à anatomia, Misra (1972) citou a presença de um pequeno feixe vascular nas cerdas do pápus de $V$. anthelmintica, os quais não ocorrem em $V$. brevifolia e $V$. herbacea, onde cada cerda é homogênea.

Um aspecto que chamou a atenção durante o presente trabalho foi a observação da freqüente presença de fungos associados às projeções das células superficiais do pápus. À primeira vista, tais fungos dão a impressão de constituírem tricomas no revestimento das cerdas, sendo necessárias observações detalhadas para sua identificação. Na literatura consultada, não foi encontrado relato deste fato em nenhuma outra espécie da família, apenas no interior de alguns tricomas glandulares das folhas de V. linearis Spreng., relatado por Sajo \& Menezes (1994), e de V. erythrophylla D.C., referido por Barroso (1970). Estudos futuros são importantes para a interpretação do significado ecológico dessa associação.

Outra estrutura relevante taxonomicamente nas Asteraceae é o carpopódio, que representa a região de abscisão da cipsela e exibe grande variação morfológica (Robinson \& King 1977). Em V. brevifolia, o carpopódio é representado por poucas camadas de células parenquimáticas, enquanto em $V$. herbacea, além de apresentar maior número de camadas, mostra ainda a formação de cristais de oxalato de cálcio. Misra (1972) e Pandey \& Singh (1980) não relataram a presença do carpopódio nas espécies avaliadas, dizendo apenas que há um espessamento maior das paredes celulares da epiderme na porção basal do fruto.

Com os dados apresentados neste trabalho, conclui-se que é possível a distinção entre $V$. brevifolia e $V$. herbacea, levando-se em conta somente os caracteres anatômicos do fruto.

Agradecimentos - À Fapesp, pelo auxílio financeiro (Proc. Biota-Fapesp n. 2000/12469-3). Ao Dr. João Semir (Departamento de Botânica, UNICAMP), pela identificação do material botânico.

\section{Referências bibliográficas}

ALMEIDA, A.M., FONSECA, C.R., PRADO, P.I., ALMEIDANETO, M., DINIZ, S., KUBOTA, U., BRAUN, M.R., RAIMUNDO, R.L.G., ANJOS, L.A., MENDONÇA, T.G., FUTADA, S.M. \& LEWINSOHN, T.M. 2005. Diversidade e ocorrência de Asteraceae em cerrados de São Paulo. Biota Neotropica 5:1-17.

BASAK, N. \& MUKHERJEE, S.K. 2003. Taxonomic significance of cypselar features in some species of Vernonia (Vernonieae - Asteraceae). Journal of Hill Resarch 16:9-15.

BARROSO, G.M. 1970. Sobre o colorido vermelho-purpúreo de Vernonia erythrophylla D.C. Boletim do Museu Paraense "Emílio Goeldi" 31:1-7.

BARROSO, G.M., MORIM, M.P., PEIXOTO, A.L. \& ICHASO, C.L.F. 1999. Frutos e sementes: morfologia aplicada à sistemática de dicotiledôneas. Editora UFV, Viçosa.

BREMER, K. 1994. Asteraceae: cladistics and classification. Timber Press, Portland.

CABRERA, A.L. 1944. Vernonieas Argentinas (Compositae). Darwiniana 6:265-379.

CARLQUIST, S. 1958. Structure and ontogeny of glandular trichomes of Madinae (Compositae). American Journal of Botany 45:675-682.

DAVIES, A.M.R. \& FACHER, E. 2001. Achene hairs and their diversity in the genus Chaetanthera Ruiz \& Pav. (Mutiseae, Asteraceae). Sendtnera 7:13-33.

DURIGAN, G., BAITELLO, J.B., FRANCO, G.A.D.C. \& SIQUEIRA, M.F. 2004. Plantas do cerrado paulista: imagens de uma paisagem ameaçada. Páginas \& Letras Editora e Gráfica, São Paulo.

FAHN, A. 1990. Plant anatomy. Pergamon Press, Oxford.

JENSEN, W.A. 1962. Botanical histochemistry: principles and practice. W.H. Freeman, San Francisco.

JOHANSEN, D.A. 1940. Plant microtechnique. McGraw-Hill, New York.

JONES, S.B. 1977. Vernonieae - systematic review. In The biology and chemistry of the Compositae (V.H. Heywood, J. B. Harborne \& B.L. Turner, eds.). Academic Press, London, v.1, p.503-521.

JOHRI, R.K. \& SINGH, C. 1997. Medicinal uses of Vernonia species. Journal of Medicinal and Aromatic Plant Sciences 19:744-752.

MACHADO, R.B., RAMOS NETO, M.B., PEREIRA, P.G.P., CALDAS, E.F., GONÇALVES, D.A., SANTOS, N.S., TABOR, K. \& STEININGER, M. 2004. Estimativas de perda da área do cerrado brasileiro. http// www.conservation.org.br/ noticias/noticia.php?id=31 (acesso 22/12/2005).

MENDONÇA, R.C., FELFILI, J.M., SILVA JÚNIOR., M.C., REZENDE, A.V., NOGUEIRA, P.E., WALTER, B.M.T. \& FILGUEIRAS, T.S. 1998. Flora vascular do cerrado. In Cerrado: ambiente e flora (S.M. Sano \& S.P. Almeida, eds.). Embrapa/CPAC, Brasília, p.289-539. 
MISRA, S. 1972. Floral morphology of the family Compositae: IV- tribe Vernonieae - Vernonia anthelmintica. Tokyo Botanical Magazine 85:187-199.

MUKHERJEE, S.K. \& SARKAR, A.K. 2001. Morphological diversity of pappus in the subfamily Asteroideae (Asteraceae). Journal of Economic and Taxonomic Botany Additional Series 19:275-295.

O'BRIEN, T.P., FEDER, N. \& MCCULLY, M.E. 1964. Polychromatic staining of plant cell walls by toluidine blue O. Protoplasma 59:368-373.

ORTIZ, S. 1999. Three new scapose species of Vernonia Schreb. (Asteraceae, Vernonieae) from Angola. Canadian Journal of Botany 77:877-883.

PANDEY, A.K. \& SINGH, R.P. 1980. Development and structure of seeds and fruits in tribe Vernonieae - some Vernonia and Elephantopus species. Flora 169:443-452.

PANDEY, A.K., SINGH, R.P. \& CHOPRA, S. 1978. Development and structure of seeds and fruits in Compositae - Cichorieae. Phytomorphology 28:198-206.

PESSONI, R.A., OLMEDO, P.M.O, CLEMENTE FILHA, A.C. \& FIGUEIREDO-RIBEIRO, R.C.L. 2004. Produção de concentrados de frutose por inulinases de Penicillium janczewskii e atividade sobre o nível de glicose plasmática em ratos diabéticos. Ciência e Tecnologia de Alimentos 24:372-377.
PIJL, L.VAN DER. 1982. Principles of dispersal in higher plants. Springer-Verlag, Berlin.

RATTER, J.A. 2004. Prefácio. In Plantas do cerrado paulista: imagens de uma paisagem ameaçada (G. Durigan, J.B. Baitello, G.A.D.C. Franco \& M.F. Siqueira, aut.). Páginas \& Letras Editora e Gráfica, São Paulo, p.vii-viii.

ROBINSON, H. \& KING, R.M. 1977. Eupatorieae, systematic review. In The biology and chemistry of the Compositae (V.H. Heywood, J.B. Harborne \& B.L. Turner, eds.). Academic Press, London, v.1, p.437-485.

ROTH, I. 1977. Fruits of angiosperms. Gebrüder Borntraeger, Berlin.

SAJO, M.G. \& MENEZES, N.L. 1994. Considerações sobre a anatomia foliar de espécies de Vernonia Screb. (Compositae) da Serra do Cipó, MG. Naturalia 19:173-183.

SANO, S.M. \& ALMEIDA, S.P. 1998. Cerrado: ambiente e flora. Embrapa/CPAC, Brasília.

SASS, J.E. 1951. Botanical microtechnique. Iowa State University, Ames.

SPJUT, R.W. 1994. A systematic treatment of fruit types. Memoirs of the New York Botanical Garden 70:1-182.

TIAGI, B. \& TAIMNI, S. 1960. Embryo-sac development in Vernonia cinerascens Schult. and seed development in V. cinerea Less. Current Science 30:406. 